\title{
Application Performance and Numerical Analysis of Phase Change Diving Suit
}

\author{
Ting Wei ${ }^{1, a}$, Zhilin Ye ${ }^{1, b}$, Baicun Zheng ${ }^{1, c}$ \\ ${ }^{1}$ Research \& Development Center for Sports Materials, \\ East China University of Science and Technology, Shanghai 200237, P.R.China \\ aweiting@ecust.edu.cn, ${ }^{\mathrm{b}}$ Zhiliny1010@foxmail.com, ${ }^{\mathrm{c} b a i c u n @ e c u s t . e d u . c n}$
}

Key words: Diving suit; Phase change; Numerical analysis

Abstract: The aim of this study was to analyze the heat transform models of phase change diving suit on the basis of the steady-heat transform theory, and determined the suitable melting temperature and latent heat of phase change materials impregnated in different suits. An insulation performance test was conducted to compare the PCM-enhanced diving suit with the conventional one. The results showed that the best melting temperature of PCMs should range from 29.2 to $35.7^{\circ} \mathrm{C}$ in the model 1 , while it could range from 24.9 to $31.4^{\circ} \mathrm{C}$ in the model 2 . If the water temperatures showed $0,5,10$ and $15^{\circ} \mathrm{C}$, according to the model 2 , the required mass of PCM- 1 in a thermal-enhanced diving suit were $0.9-2.5,0-1.3,0-0.04$ and $0 \mathrm{~kg}$, respectively; the corresponding values of PCM-2 were 1.0-2.8, 0-1.5, 0-0.05 and $0 \mathrm{~kg}$, respectively. From the application performance test, the insulation time last for $61 \mathrm{~min}$ at $25^{\circ} \mathrm{C}$, and $83 \mathrm{~min}$ at $20^{\circ} \mathrm{C}$ for the conventional diving suit. While it last for about $68 \mathrm{~min}$ at $25^{\circ} \mathrm{C}$, and $98 \mathrm{~min}$ at $20^{\circ} \mathrm{C}$ for the thermal-enhanced diving suit with PCM-2; and it last for about $81 \mathrm{~min}$ at $25^{\circ} \mathrm{C}$, and $116 \mathrm{~min}$ at $20^{\circ} \mathrm{C}$ for thermal-enhanced diving suit with PCM-1. All demonstrates the effectiveness of the PCMs used in the garments on improving thermal protection in the cold exposure.

\section{Introduction}

Sports can help human keep fit and construct characters like self-confidence, perseverance, responsibility and loyalty. However, there possibly exist sports injuries, so different sport goods need to be used in different sports. The diving suit is one of the most important diving equipments, because it can protect divers or athletes from cold water, which may make body move hard, or cause serious injury, even endanger the lives. With the development of diving in the deeper and colder ocean condition, a novel garment should be more comfortable, more efficient, lighter and warmer.

Currently, there are three kinds of thermal enhanced diving suits ${ }^{[1-3]}$, one is heated with hot water, another is heated with electricity, and the third is heated with phase change materials (PCMs). The last one can release or store energy acting as a thermal buffer to provide divers thermal protection, and it's also energy saving, lightweight, and easy to control. Although it is the most promising candidate for thermal-enhanced suit, the widespread application is still restricted by major drawbacks such as service life and cost. Therefore, the numerical research on diving suit heated with PCMs is very meaningful and prospective ${ }^{[4]}$.

This work analyzed two models for body- PCMs enhanced diving suit-cold environment on the basis of the steady-state heat transfer process. This effort provided the guildlines and recommendations for materials selection and garment design. Meanwhile, an insulation performance test was conducted to compare the PCM-enhanced diving suit with the conventional one. 


\section{Thermal models}

Model $1:$ Body-PCMs enhanced diving suit-environment heat transfer model

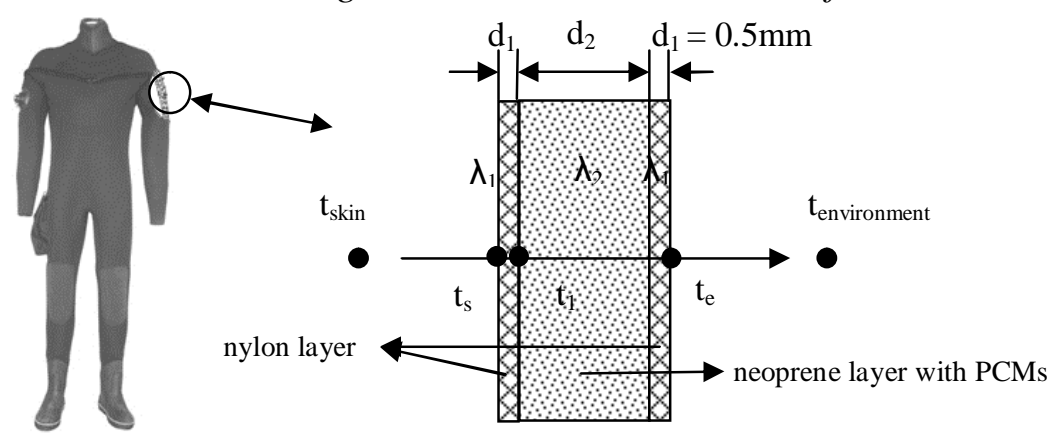

Fig. 1 Heat transfer model of body- PCMs enhanced diving suit - environment

The heat transfer process of body-clothing-environment is very complex. It is related not only to the clothes structure and fiber characteristics, but also to the thermal radiation and the air layer thickness. During the diving process, the heat transfer among body-diving suit-environment is mainly influenced by the thermal conductivity of the diver's clothes. If the diver only dresses a PCM-enhanced garment, the heat transfer can be calculated as follows ${ }^{[5]}$.

$$
Q=0.382 \lambda A T \bullet(\Delta t / d)
$$

The formula (1) can be deformed to express the heat flux:

$$
q=\frac{Q}{A T}=0.382 \frac{\Delta t}{(d / \lambda)}
$$

Where $\mathrm{Q}$ is the conduction heat $(\mathrm{J}) ; \lambda$ is the clothes thermal conductivity $\left(\mathrm{W} / \mathrm{m} \cdot{ }^{\circ} \mathrm{C}\right)$; $\mathrm{A}$ is the transfer surface area $\left(\mathrm{m}^{2}\right)$; $\mathrm{T}$ is the transfer time $(\mathrm{h}) ; \Delta \mathrm{t}$ is the temperature difference between layers $\left({ }^{\circ} \mathrm{C}\right)$; $\mathrm{d}$ is the clothes thickness $(\mathrm{m})$; $\mathrm{q}$ is the heat flux $\left(\mathrm{W} / \mathrm{m}^{2}\right)$.

Assuming the metabolic heat in the sport is about $180 \mathrm{~W}$ and a diver's skin surface area is about $1.77 \mathrm{~m}^{2}$, then the body heat flux $\mathrm{q}_{\mathrm{s}}$ is $101.7 \mathrm{~W} / \mathrm{m}^{2}{ }^{[6]}$. In this research, supposing that the inner nylon layer $\lambda_{1}$ is $0.26 \mathrm{~W} / \mathrm{m} \bullet{ }^{\circ} \mathrm{C}, \mathrm{d}_{1}$ is $0.5 \mathrm{~mm}$ (Fig. 1$)$, the heat flux $\mathrm{q}\left(\mathrm{q}=\mathrm{q}_{\mathrm{s}}\right)$ is $101.7 \mathrm{~W} / \mathrm{m}^{2}$, as well as the comfortable temperature for human body is from 29.2 to $35.7^{\circ} \mathrm{C}$, the temperature $\mathrm{t}_{1}$ of neoprene layer containing PCMs should be from 28.7 to $35.2^{\circ} \mathrm{C}$ that is also the best melting temperature for phase change material.

Model 2: Body-underwear- PCMs enhanced diving suit- environment heat transfer model

If water is too cold, more clothes should be employed to improve the thermal effect. Then the transfer process among body-clothing-environment meets multilayer heat transfer mechanism which can be simplified by the steady-state heat conduction process of multilayer planes. If a cotton underwear is added under the PCMs-enhanced diving suit, the model can be shown in Fig.2 and the formula is following ${ }^{[5]}$ :

$$
t_{2}=t_{s}-\frac{q}{0.382} \bullet\left(\frac{d_{1}}{\lambda_{1}}+\frac{d_{3}}{\lambda_{3}}\right)
$$

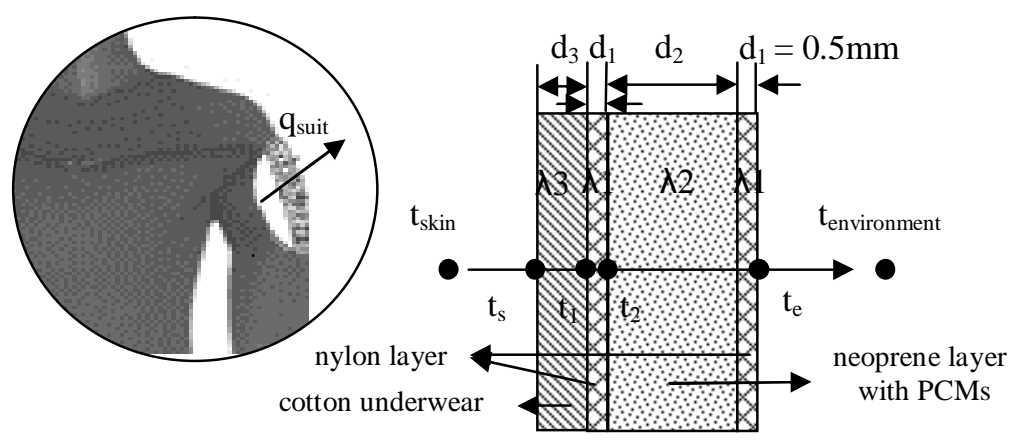

Fig. 2 Heat transfer model of body - underwear - diving suit - environment

For $\lambda_{1}$ is $0.26 \mathrm{~W} / \mathrm{m} \bullet{ }^{\circ} \mathrm{C}, \mathrm{d}_{1}$ is $0.5 \mathrm{~mm}$ (Fig.2), and the heat flux $\mathrm{q}\left(\mathrm{q}=\mathrm{q}_{\mathrm{s}}\right.$ ) is $101.7 \mathrm{~W} / \mathrm{m}^{2}$, 
assuming the thermal conductivity of the cotton layer $\lambda_{3}$ is $0.071 \mathrm{~W} / \mathrm{m} \bullet{ }^{\circ} \mathrm{C}{ }^{[5]}$ and the cotton layer thickness $d_{3}$ is $1 \mathrm{~mm}$, the node temperature $t_{2}$ (in the Fig. 2) of neoprene layer ranges from 24.9 to $31.4^{\circ} \mathrm{C}$ that is also the suitable melting temperature for phase change material.

\section{Results and discussion}

The calculated heat of PCMs impregnated in the diving suit

The aim of PCMs-enhanced diving suit is to make the diver warm and comfortable. For the whole system, the thermal equilibrium is following ${ }^{[7]}$ :

$$
q_{P C M}+q_{s}=0.382 \frac{t_{s}-t_{n}}{\sum d_{n} / \lambda_{n}}
$$

While the effective surface area covered by diving suit is $1.53 \mathrm{~m}^{2}$, saying $86.9 \%$ of the whole body surface area $1.77 \mathrm{~m}^{2}$, the heat (QPCM) produced by the PCMs can be calculated by the formula [6]:

$$
Q_{P C M}=1.53 \times q_{P C M}
$$

Table 1 Thickness and thermal conductivity parameters

\begin{tabular}{ccc}
\hline Clothing layer & Thickness $\mathrm{d}(\mathrm{mm})$ & Thermal conductivity $\lambda\left(\mathrm{W} / \mathrm{m} \cdot{ }^{\circ} \mathrm{C}\right)$ \\
\hline Cotton underwear layer & 1.0 & 0.071 \\
Neoprene layer with PCMs & 3 & 0.090 \\
Neoprene layer with PCMs & 5 & 0.064 \\
nylon layer & 0.5 & 0.26 \\
\hline
\end{tabular}

The needed heat flux q $_{\mathrm{PCM}}$ and heat $\mathrm{Q}_{\mathrm{PCM}}$ can be calculated by the formulae (4-5) and they are showed in Table 2, on the conditions that the comfortable skin temperature keeps in the range of 29.2 to $35.7{ }^{\circ} \mathrm{C}$, the water temperatures range from 0 to $15{ }^{\circ} \mathrm{C}$, and thickness and thermal conductivity parameters are showed in Table 1 . All the values indicate that $\mathrm{q}_{\mathrm{PCM}}$ and $\mathrm{Q}_{\mathrm{PCM}}$ needed in the $5 \mathrm{~mm}$ neoprene layer are much smaller than that in the $3 \mathrm{~mm}$ neoprene layer.

Table 2 The needed heat flux and heat production by PCMs

\begin{tabular}{cccc}
\hline $\begin{array}{c}\text { Neoprene layer thickness } \\
\mathrm{d}_{2} / \mathrm{mm}\end{array}$ & $\begin{array}{c}\text { Water temperature } \\
\mathrm{t}_{\mathrm{e}}\left({ }^{\circ} \mathrm{C}\right)\end{array}$ & $\begin{array}{c}\text { Heat flux of PCMs } \\
\mathrm{q}_{\mathrm{PCM}}\left(\mathrm{W} / \mathrm{m}^{2}\right)\end{array}$ & $\begin{array}{c}\text { Heat of PCMs } \\
\mathrm{QPCM}(\mathrm{W})\end{array}$ \\
\hline 3 & 0 & $116.2 \sim 164.7$ & $177.8 \sim 252.0$ \\
& 5 & $78.9 \sim 127.4$ & $120.7 \sim 194.9$ \\
& 10 & $41.6 \sim 90.1$ & $63.6 \sim 137.8$ \\
& 15 & $4.3 \sim 52.8$ & $6.5 \sim 80.7$ \\
5 & 0 & $14.6 \sim 40.5$ & $22.4 \sim 62.0$ \\
& 5 & $0 \sim 20.6$ & $0 \sim 31.5$ \\
& 10 & $0 \sim 0.7$ & $0 \sim 1.1$ \\
& 15 & 0 & 0 \\
\hline
\end{tabular}

The calculated mass of PCMs needed in the diving suit

The mass of PCMs added in a diving suit is an important parameter in the suit designing process, since the weight percentage should be smaller when the insulation performance keeps well. If the athlete dives for $1 \mathrm{~h}$, the PCMs mass can be calculated by the following formula:

$$
M=\frac{Q_{P C M} \times 3600}{\Delta H_{f}}
$$

Where $\mathrm{M}$ is the total mass of PCMs added in a diving suit, g; $\mathrm{Q}_{\mathrm{PCM}}$ is the heat energy produced by PCMs in the suit, $\mathrm{W} ; \Delta \mathrm{H}_{\mathrm{f}}$ is the latent heat of PCMs, J/g. 


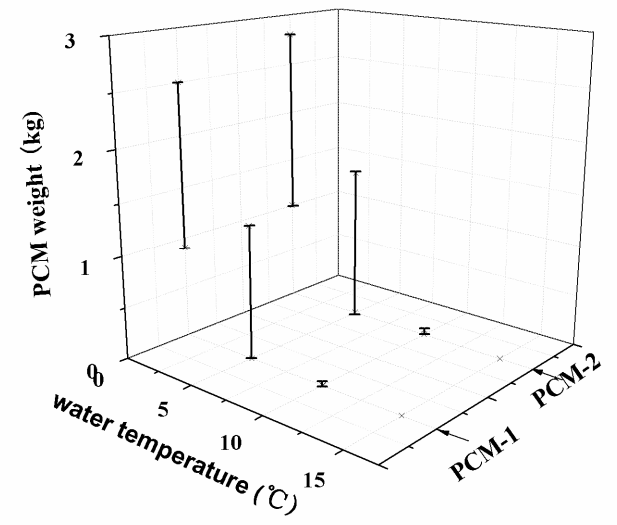

Fig. 3 The mass of PCMs needed in a diving-suit exposed in different water temperatures

There are two kinds of PCMs used in this research, i.e. the melting temperatures of PCM-1 and PCM-2 are $33.6{ }^{\circ} \mathrm{C}$ and $29.6{ }^{\circ} \mathrm{C}$ while the latent heats of PCM- 1 and PCM-2 are $90 \mathrm{~J} / \mathrm{g}$ and $80 \mathrm{~J} / \mathrm{g}$, respectively. According to the model 2, the required mass of PCM-1 in a thermal-enhanced diving suit is $0.9 \sim 2.5,0 \sim 1.3,0 \sim 0.04$ and $0 \mathrm{~kg}$ when the water temperatures show $0,5,10$ and $15^{\circ} \mathrm{C}$, respectively; the corresponding values of PCM-2 are $1.0 \sim 2.8,0 \sim 1.5,0 \sim 0.05$ and $0 \mathrm{~kg}$, respectively.

The insulation performance of the PCMs-enhanced diving suit

The insulation performance was conducted by the gradual cooling test ${ }^{[5]}$ in a water bath of $5^{\circ} \mathrm{C}$ to compare the PCMs-enhanced diving suits with the conventional one. From Fig.4, it can be seen that the cooling rate of the common diving suit is obviously faster than that of PCMs-enhanced ones, for the reason that the latent heat produced by the PCMs can prolong the insulation time. When the phase transition completes, the cooling rates of thermal-enhanced ones increase, too. For the conventional diving suit, the insulation time can last for $61 \mathrm{~min}$ at $25^{\circ} \mathrm{C}$, and $83 \mathrm{~min}$ at $20^{\circ} \mathrm{C}$. While it can last for about $68 \mathrm{~min}$ at $25^{\circ} \mathrm{C}$, and $98 \mathrm{~min}$ at $20^{\circ} \mathrm{C}$ for the thermal-enhanced diving suit with PCM-2; and it can last for about $81 \mathrm{~min}$ at $25^{\circ} \mathrm{C}$, and $116 \mathrm{~min}$ at $20^{\circ} \mathrm{C}$ for the thermal-enhanced diving suit with PCM-1. Those results demonstrate the effectiveness of the PCMs used in the garments on improving thermal protection in the cold exposure.

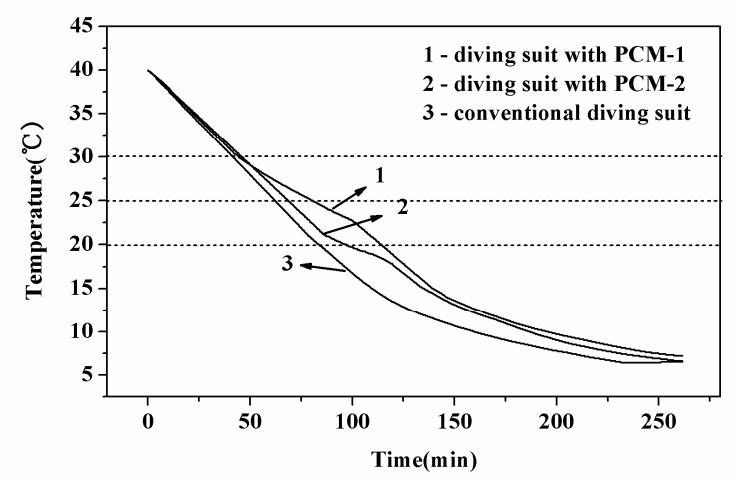

Fig. 4 The insulation performances of different diving suits

\section{Conclusion}

This research focused on the application performance and the numerical analysis of phase change diving suit. On the basis of the steady-heat transform theory, it analyzed two models for bodyPCMs enhanced diving suit-cold environment, and determined the suitable melting temperature and latent heat of phase change material impregnated in the suits. This effort provided the guildlines and recommendations for materials selection and garment design. Meanwhile, an insulation performance test was conducted to compare the PCM-enhanced diving suit with the conventional 
one, and it demonstrated the effectiveness of the PCMs used in the garments on improving the thermal protection in cold exposure.

\section{References}

[1] Jinghua Gu, Ping Ni. Characteristics and development trend on diviony suit[J]. China Personal Protective Equipment, 2006, 2: 45-47.

[2] Hasnain SM. Review on sustainable thermal energy storage technologies. Part I: heat storage materials and techniques. Energy conversion and Management, 1998(11)39: 1127-1138.

[3] Mondal S. Phase change materials for smart textiles-An overview[J]. Applied Thermal Engineering, 2008(11-12) 28: 1536-1550.

[4] Nuckols M L. Analytical modeing of a diver dry suit enhanced with micro-encapsulated phase change materials[J]. Ocean Engineering, 1999, (26): 547-564.

[5] Weiyuan Zhang. Clothing comfort and function [M]. Beijing: China Textile \& Apparel Press, 2005.

[6] Yongmei $\mathrm{Hu}$, Xiaoluo $\mathrm{Wu}$, Zhihong $\mathrm{Hu}$, et al. Stuy on formula for calculating body surface areas of the chinese adults [J]. Acta Physiologica Sinica, 1999, 51(1): 45-48.

[7] Meiwu Shi, Yan Zhang. The possible application and subsequent research on PCM in the intelligent insulation clothing PCM [J]. Jinan Man-mad Fibre Technology, 2006, (3): 16-19. 